\title{
Pemutuan Fisik Gabah dan Beras Menurut Standar Nasional Indonesia (SNI)
}

\author{
Physical Qualifications of Grain dan Rice According to Indonesian National \\ Standards (SNI)
}

\author{
Author(s): Sri Lestari ${ }^{(1) *}$; Fajar Kurniawan ${ }^{(2)}$ \\ (1) Balai Pengkajian Teknologi Pertanian \\ (2) Balai Besar Penelitian dan Pengembangan Pasca Panen \\ * Corresponding author: slestariapril@gmail.com
}

\section{Submitted: 25 Jul 2021 Accepted: 04 Sep $2021 \quad$ Published: 30 Sep 2021}

\begin{abstract}
ABSTRAK
Pemutuan gabah dan beras sangat diperlukan guna mengetahui kualitas gabah dan beras yang dihasilkan serta untuk menentukan nilai jual. Tujuan dari penelitian ini yaitu untuk menganalisis mutu fisik gabah dan beras serta menilai mutu gabah menurut SNI 1987 dan mutu beras menurut SNI 6128-2015. Bahan yang digunakan pada penelitian ini adalah gabah kering giling (GKG) varietas IPB $3 \mathrm{~S}$ dan beras varietas padi Ciherang. Masing-masing sampel yang digunakan sebanyak 100 gram dengan 4 kali ulangan. Parameter pengukuran mutu fisik gabah meliputi kadar air, gabah hampa, butir rusak (kuning), butir mengapur (gabah muda) serta gabah merah. Sedangkan parameter pengukuran mutu fisik beras meliputi kadar air, persentase beras kepala, butir patah, butir menir, butir merah, butir kuning (rusak), butir kapur, benda asing dan butir gabah. Hasil penelitianmenunjukkan bahwagabah varietas IPB 3S memiliki kadar air sebesar $14.55 \%$, gabah hampa $1.64 \%$, butir mengapur (gabah muda) sebesar 3.12\%, butir rusak (kuning) sebesar $4.46 \%$ dan butir merah sebesar $0 \%$. Sedangkan komponen mutu fisik beras varietas padi Ciherang memiliki kadar air sebesar $14.3 \%$, butir kepala sebesar $66.73 \%$, butir patah sebesar $24.18 \%$, butir menir sebesar $7.21 \%$, butir mengapur sebesar $1.51 \%$, butir kuning (rusak) sebesar $0.21 \%$, butir merah sebesar $0.01 \%$, benda asing $0 \%$ serta butir gabah $0 \%$. Pemutuan gabah varietas IPB 3S berada pada kategori gabah Mutu II, sedangkan beras varietas padi Ciherang tidak sesuai dengan SNI beras dikarenakan tingginya persentase beras menir.
\end{abstract}

\section{Kata Kunci:}

beras,

gabah,

pemutuan,

SNI

\begin{abstract}
Keywords: $\quad$ The quality of grain and rice is needed to determine the quality of the grain and rice produced grain, quality, rice, SNI
\end{abstract}




\section{PENDAHULUAN}

Penggilingan padi memiliki peran yang strategis dalam pemenuhan kebutuhan pangan yang merupakan salah satu kebutuhan pokok manusia. Penggilingan padi merupakan proses pengolahan gabah menjadi beras dengan batas kadar air 13-14 \% (Umar, 2011). Menurut Thahir (2010), rendemen beras giling (milling recovery) adalah presentase bobot/ bobot beras giling yang dapat diperoleh dari sejumlah gabah bernas, dalam keadaan bersih, tidak mengandung gabah hampa dan kotoran pada kadar air $14 \%$. Penggilingan padi sebagai mata rantai akhir dari proses produksi beras, mempunyai posisi yang strategis untuk ditingkatkan kinerja dan efisiensinya sehingga dapat menyumbang pada peningkatan produksi beras.

Mutu gabah dipengaruhi oleh berbagai faktor seperti keadaan lingkungan tumbuh, budidaya, panen hingga penanganan pascapanen dan faktor genetik tanaman (Kumar et al., 2016). Menurut Mardiah et al. (2016), mutu beras dipengaruhi oleh gabungan dari karakter fisik, kimia, dan nutrisi.

Masalah utama yang sering dialami oleh petani dalam penanganan pascapanen padi adalah tingginya kehilangan hasil selama pascapanen. Kegiatan pascapanen meliputi proses pemanenan padi, penyimpanan padi, perontokan padi, pengeringan gabah, dan penggilingan gabah hingga menjadi beras. Susut atau looses dapat dibagi menjadi 2 kategori yaitu susut kuantitas dan susut kualitas. Susut kuantitas disebabkan karena hasil panen banyak tercecer pada berbagai kegiatan mulai dari panen hingga pascapanen. Susut kualitas berkaitan dengan susut mutu yang diakibatkan oleh penanganan hasil panen yang kurang baik misalnya saja pada saat setelah penjemuran kadar air gabah terlalu rendah sehingga menyebabkan gabah ketika digiling menghasilkan beras menir yang relatif lebih banyak.

Besarnya persentase rendemen beras kepala merupakan factor utama dalam penentuan mutu gabah dan beras disebabkan olehpenentuan jumlah kilogram beras yang akan dijual (David $\mathrm{H}$ \& Kartinaty, 2019). Hal ini tentu saja dipengaruhi oleh rantai kegiatan penanganan gabah itu sendiri. Diperlukan adanya evaluasi lebih lanjut mengenai penanganan pascapanen gabah menjadi beras agar produsen dan para pemegang kebijakan mengetahui hasilnya untuk selanjutnya secara bersama-sama mencari solusi agar looses akibat penanganan pascapanen khususnya pada mata rantai penggilingan gabah menjadi beras dapat ditekan sekecil mungkin.

Tujuan dari penelitian ini yaitu untuk menganalisis mutu fisik gabah dan beras serta menilai mutu gabah menurut SNI 1987 dan mutu beras menurut SNI 61282015.

\section{METODOLOGI}

\section{Waktu dan Tempat}

Penelitian dilaksanakan pada September 2018 yang bertempat di Laboratorium Leuwikopo, Fakultas Teknologi Pertanian, Institut Pertanian Bogor (IPB), Bogor.

\section{Alat dan Bahan}

Bahan yang digunakan pada kegiatan penelitian ini adalah gabah kering giling $(\mathrm{GKG})$ varietas IPB 3S, beras dari varietas beras Ciherang serta alkohol 95\%. Alat-alat yang digunakan untuk pengeringan adalah alat pengupas sekam (husker) merk Satake, silinder separator merk Satake, timbangan digital, Crown Digital Moisture Meter, ayakan menir, ayakan beras patah, saringan, gelas ukur, pinset, kertas buram, dan wadah. 


\section{Parameter Pengukuran}

Masing-masing sampel gabah dan beras yang digunakan sebanyak 100 gram dengan 4 kali ulangan. Parameter pengukuran mutu fisik gabah meliputi kadar air, gabah hampa, butir rusak (kuning), butir mengapur (gabah muda) serta gabah merah. Sedangkan parameter pengukuran mutu fisik beras meliputi kadar air, persentase beras kepala, butir patah, butir menir, butir merah, butir kuning, butir kapur, benda asing dan butir gabah. Data ditabulasi dengan menggunakan Microsoft Excel.

\section{Prosedur Kerja}

a. Penggilingan Gabah

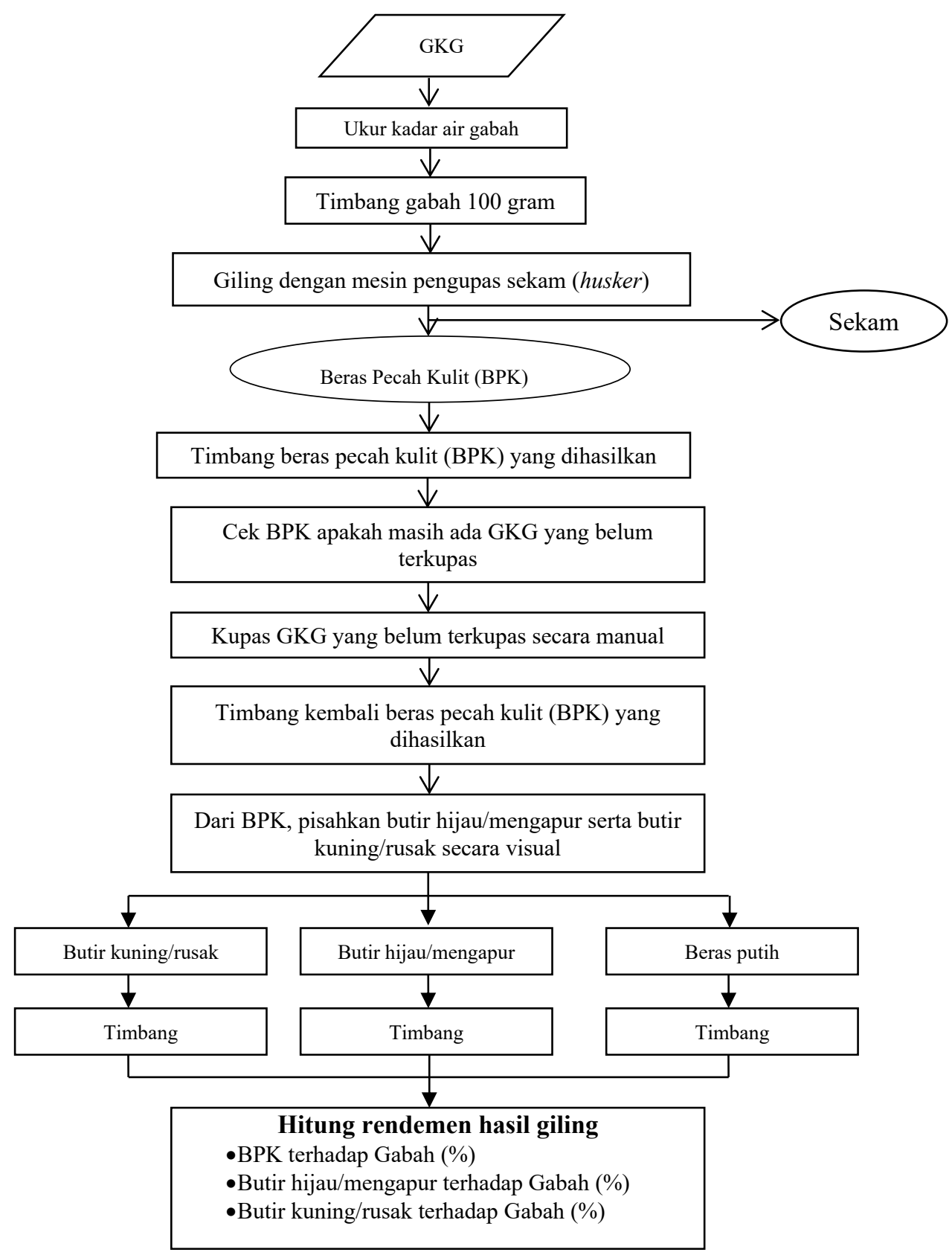

Gambar 1. Diagram Alir Prosedur Penggilingan Gabah

Figure 1. Flowchart of Grain Milling Procedure 
b. Pemutuan gabah dengan menggunakan alkohol

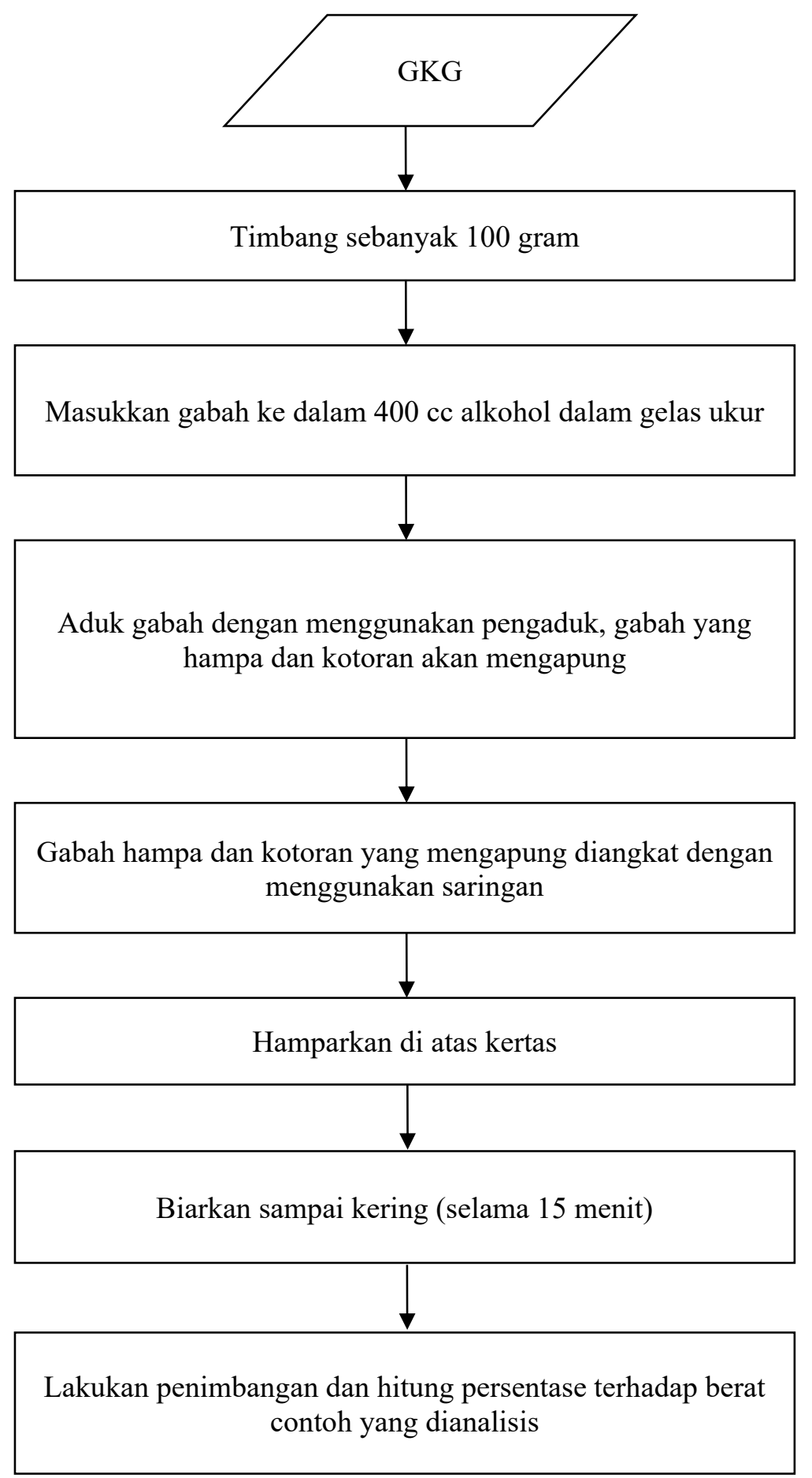

Gambar 2. Diagram Alir Proses Pemutuan Gabah Menggunakan Alkohol

Figure 2. Flowchart of The Grain Quality Process Using Alcohol 


\section{c. Pemutuan Beras}

Komponen mutu gabah dan beras yang dihasilkan kemudian dibandingkan dengan komponen mutu gabah sesuai SNI 1987 (Tabel 1) dan beras mengacu kepada standar mutu beras yang ditetapkan oleh Standar Nasional Indonesia (SNI 6128-2015) (Tabel 2).

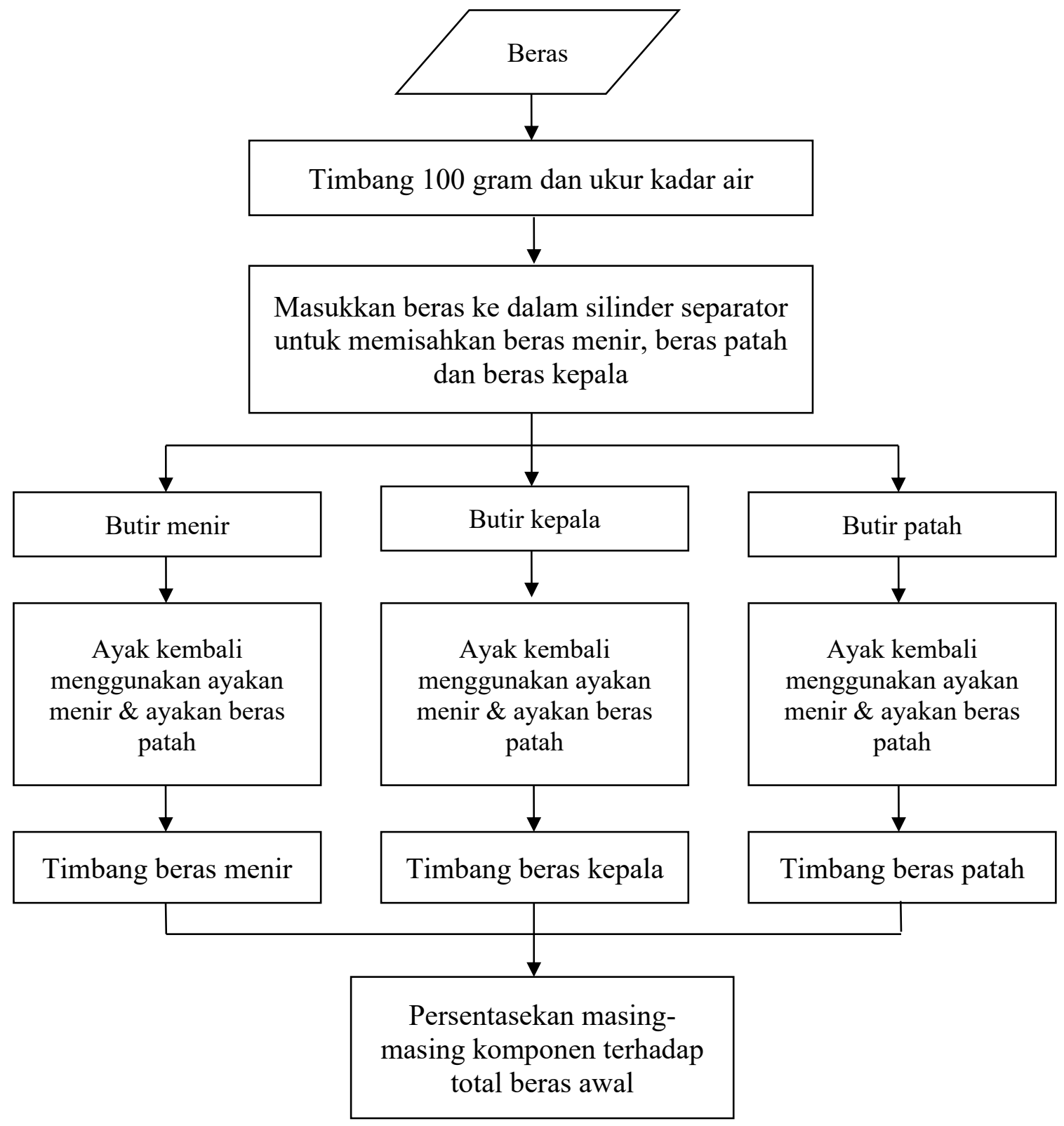

Gambar 3. Prosedur Pemutuan Beras

Figure 3. Rice Grading Procedure 
Tabel 1. Persyaratan Mutu Gabah Menurut SNI 1987

Table 1. Grain Quality Requirements According to SNI 1987

\begin{tabular}{lccc}
\hline \multicolumn{1}{c}{ Kriteria Mutu } & Mutu I (\%) & $\begin{array}{c}\text { Mutu II } \\
(\%)\end{array}$ & Mutu III (\%) \\
\hline Kadar air (maks) & 14 & 14 & 14 \\
Gabah hampa & 1 & 2 & 3 \\
Butir rusak + butir kuning (maks) & 2 & 5 & 7 \\
Butir mengapur + gabah muda (maks) & 1 & 5 & 10 \\
Gabah merah (maks) & 1 & 2 & 4 \\
Benda asing (maks) & - & 2 & 4 \\
Gabah varietas lain (maks) & 2 & 5 & 10 \\
\hline
\end{tabular}

Tabel 2. Persyaratan Mutu Beras Menurut SNI 6128: 2015

Table 2. Rice Quality Requirements According to SNI 6128:2015

\begin{tabular}{cccrrrr}
\hline & & & \multicolumn{4}{c}{ Kelas Mutu } \\
\cline { 4 - 7 } No & \multirow{2}{*}{ Komponen Mutu } & Satuan & Premium & \multicolumn{3}{c}{ Medium } \\
\cline { 4 - 7 } & & $(\%)$ & 100 & 95 & 90 & 80 \\
\hline 1 & Derajat sosoh (min) & $(\%)$ & 14 & 14 & 14 & 15 \\
2 & Kadar air (maks) & $(\%)$ & 95 & 78 & 73 & 60 \\
3 & Beras kepala (min) & $(\%)$ & 5 & 20 & 25 & 30 \\
4 & Butir patah (maks) & $(\%)$ & 0 & 2 & 2 & 5 \\
5 & Butir menir (maks) & $(\%)$ & 0 & 2 & 3 & 3 \\
6 & Butir merah (maks) & $(\%)$ & 0 & 2 & 3 & 5 \\
7 & Butir kuning rusak (maks) & $(\%)$ & 0 & 2 & 3 & 5 \\
8 & Butir kapur (maks) & $(\%)$ & 0 & 0.02 & 0.05 & 0.20 \\
9 & Benda asing (maks) & $($ butir/100 g) & 0 & 1 & 2 & 3 \\
10 & Butir gabah (maks) & &
\end{tabular}

Sumber: BSN 2015 dalam David H \& Kartinaty, (2019)

Source: BSN (2015)in David H \& Kartinaty, (2019)

\section{HASIL DAN PEMBAHASAN}

\section{Pemutuan Gabah}

Kualitas fisik gabah yang diamati mulai dari pemanenan hingga penggilingan meliputi kadar air gabah, dimensi dan penampakan gabah, gabah bernas dan gabah hampa serta keretakan gabah. Kualitas fisik gabah tersebut akan mempengaruhi besar kecilnya rendemen penggilingan yang dihasilkan (Hasbullah \& Dewi, 2009). Setiawati (2020) melaporkan bahwa mutu gabah di Indonesia dipengaruhi signifikan oleh faktor kadar air, kadar gabah hampa dan varietas gabah. Hasil penelitian Sartika \& Ramdhani, (2018) menunjukkan bahwa varietas padi berpengaruh nyata terhadap rendemen dan susut giling. Menurut Hasbi (2012), kualitas gabah dan beras dipengaruhi oleh penanganan pasca panen yang kurang tepat sehingga dapat menurunkan kualitas maupun kuantitas dari gabah dan beras itu sendiri.

Hasil analisis mutu gabah ditunjukkan oleh Tabel 3. Dari data dapat diketahui bahwa dengan mengacu pada standar mutu gabah SNI 1987, gabah 
varietas IPB $3 \mathrm{~S}$ termasuk ke dalam kategori Gabah Mutu II dengan syarat dilakukan penurunan kadar air sebesar $0.55 \%$. Banyaknya jumlah butir kuning/rusak diduga dipengaruhi oleh kadar air gabah yang nilainya $>14 \%$.

$$
\text { Rendemen giling banyak }
$$

dipengaruhi oleh bahan bakunya yaitu gabah kering giling. Menurut Thahir (2010), rendemen giling didapatkan dari persentase beras giling yang diperoleh dari gabah yang bersih (tanpa gabah hampa dan kotoran gabah). Makin bernas gabah kering giling dengan kandungan butir hampa dan kotoran rendah akan makin tinggi rendemen gilingnya. Menurut Indrasari et al. (2016), rendemen giling berkorelasi positif dengan rendemen beras pecah kulit (BPK), makin tinggi rendemen gilingnya maka makin tinggi rendemen beras pecah kulitnya. Dengan kata lain, rendemen beras giling yang rendah menunjukkan kualitas gabah kering giling yang rendah. Faktor yang berpengaruh

Tabel 3. Hasil Analisis Mutu Gabah

Table 3. Results of Grain Quality Analysis terhadap rendemen giling antara lain kadar air gabah yang rendah $(<14 \%)$ dan tidak merata, serta kandungan gabah hampa dan kotoran yang tinggi.Kadar air gabah merupakan komponen utama yang harus diperhatikan bila akan melakukan proses penggilingan untuk menghasilkan beras giling. Kadar air yang tidak tepat pada pelaksanaan proses penggilingan akan berpengaruh langsung terhadap derajat sosoh, rendemen giling dan mutu beras yang dihasilkan. Penggilingan yang dilakukan pada kadar air yang rendah akan menyebabkan tingginya persentase beras pecah, menir dan bekatul, sehingga menyebabkan penurunan rendemen giling.

Menurut Munarso et al.(2020), pemutuan beras dan gabah sangat penting dilakukan mengingat jika tidak sesuai dengan standar maka akan mempengaruhi keamanan dari produk itu sendiri, terutama ketika memasuki tahap proses penyimpanan.

\begin{tabular}{rlrrrrrr}
\hline \multirow{2}{*}{ No } & \multirow{2}{*}{ Komponen Mutu } & \multirow{2}{*}{ Satuan } & \multicolumn{1}{c}{ Ulangan } & \multirow{2}{*}{ Rata-Rata } \\
\cline { 4 - 7 } & & & \multicolumn{1}{c}{2} & \multicolumn{1}{c}{3} & \multicolumn{1}{c}{4} & \\
\hline 1 & Kadar air & $\%$ & 14.70 & 14.40 & 14.70 & 14.40 & 14.55 \\
2 & Gabah hampa/kotoran & $\%$ & 0.63 & 1.53 & 2.34 & 2.07 & 1.64 \\
3 & Butir hijau/mengapur & $\%$ & 3.94 & 4.45 & 1.38 & 2.72 & 3.12 \\
4 & Butir kuning/rusak & $\%$ & 2.34 & 3.21 & 44.90 & 7.38 & 4.46 \\
5 & Butir merah & $\%$ & 0.00 & 0.00 & 0.00 & 0.00 & 0.00 \\
6 & Gabah tenggelam & $\%$ & 99.37 & 98.47 & 97.66 & 97.93 & 98.36 \\
7 & Berat gabah awal & gr & 100.08 & 100.80 & 100.95 & 100.13 & 100.49 \\
8 & Beras pecah kulit & gr & 73.45 & 74.36 & 71.89 & 77.47 & 74.29 \\
9 & Rendemen BPK & $\%$ & 73.39 & 73.77 & 71.21 & 77.37 & 73.94 \\
10 & Rendemen giling & $\%$ & 73.86 & 74.91 & 72.90 & 79.00 & 75.17 \\
\hline
\end{tabular}

\section{Pemutuan Beras}

Beras kepala adalah butiran beras yang mempunyai ukuran $0,6-1,0$ bagian dari ukuran beras utuh. Kualitas beras giling sangat ditentukan oleh banyaknya kandungan beras kepala. Beras giling dengan kandungan beras kepala antara 95-
$100 \%$ dapat dikelompokkan ke dalam beras mutu premium. Beras patah adalah butiran beras yang mempunyai ukuran 0,2 0,6 bagian dari ukuran beras utuh. Sedangkan menir adalah beras patah yang mempunyai ukuran kurang dari 0,2 bagian dari ukuran beras utuh. Kualitas beras 
giling sangat ditentukan oleh banyaknya kandungan beras patah dan menir. Tingginya persentase beras patah dan menir juga akan berpengaruh terhadap rendahnya harga jual maupun cita rasa nasi. Menurut Indrasari et al., (2016), banyaknya persentase beras patah dan menir dipengaruhi oleh kadar air gabah yang tinggi $(>14 \%)$ atau rendah $(<14 \%)$. MenurutSarastuti et al. (2018), kadar air beras senilai $>14 \%$ diduga dipengaruhi oleh kadar air gabahnya.

Berdasarkan data Tabel 4, dapat diketahui bahwa mutu beras yang diamati tidak sesuai dengan kriteria SNI mutu beras (SNI 6128-2015). Hal ini dikarenakan persentase beras menir yang dihasilkan mencapai $7.22 \%$, padahal SNI mempersyaratkan menir maksimal sebesar 5\% (untuk kategori mutu Medium 3). Menurut Nugraha (2009) bahwa rendemen giling banyak dipengaruhi oleh bahan bakunya yaitu gabah kering giling. Makin bernas gabah kering giling dengan kandungan butir hampa dan kotoran rendah akan makin tinggi rendemen gilingnya. Dengan kata lain, rendemen beras giling yang rendah menunjukkan kualitas gabah kering giling yang rendah. Faktor yang berpengaruh terhadap rendemen giling antara lain kadar air gabah yang tidak merata, serta kandungan gabah hampa dan kotoran yang tinggi. Menurut Umar (2011), semakin tinggi kadar air (>14\%) maka persentase beras menir yang dihasilkan akan semakin besar.

Tabel 4. Hasil Analisis Mutu Beras

Table 4. Results of Rice Quality Analysis

\begin{tabular}{clrrrrrr}
\hline \multirow{2}{*}{ No } & \multirow{2}{*}{ Komponen Mutu } & \multirow{2}{*}{ Satuan } & \multicolumn{7}{c}{ Ulangan } & \multirow{2}{*}{ Rata-Rata } \\
\cline { 4 - 7 } & & & \multicolumn{1}{c}{2} & \multicolumn{1}{c}{3} & \multicolumn{1}{c}{4} & \\
\hline 1 & Kadar air & $\%$ & 14.5 & 14.2 & 14.2 & 14.3 & 14.3 \\
2 & Berat beras awal & gr & 100 & 100.8 & 100.3 & 100 & 100.28 \\
3 & Butir kepala & $\%$ & 68.53 & 64.15 & 65.59 & 68.65 & 66.73 \\
4 & Butir utuh & $\%$ & 0 & 0 & 0 & 0 & 0 \\
5 & Butir patah & $\%$ & 22.75 & 26.72 & 24.38 & 23.46 & 24.33 \\
6 & Butir menir & $\%$ & 5.73 & 7.91 & 7.71 & 7.52 & 7.22 \\
7 & Butir mengapur/hijau & $\%$ & 2.88 & 0.89 & 2.26 & 0 & 1.51 \\
8 & Butir rusak/kuning & $\%$ & 0.11 & 0.29 & 0.06 & 0.37 & 0.21 \\
9 & Butir merah & $\%$ & 0 & 0.04 & 0 & 0 & 0.01 \\
10 & Benda asing & $\%$ & 0.00 & 0.00 & 0.00 & 0.00 & 0.00 \\
11 & Butir gabah & $($ butir/ & 0.00 & 0.00 & 0.00 & 0.00 & 0.00 \\
\hline
\end{tabular}

Menurut Yuriansyah (2017), menir memiliki ukuran 0.25 bagian dari beras yang utuh. Menurut Ulfa et al. (2014) tingginya persentase beras menir disebabkan oleh proses pengeringan yang kurang sempurna dan lamanya waktu penyosohan. Meskipun beras varietas padi Ciherang tidak termasuk ke dalam kategori kelas manapun dikarenakan tingginya persentase beras menir, tidak menutup kemungkinan dilakukannya usaha agar nilai jual berasnya dapat bernilai ekonomis. Salah satu usaha yang dapat dilakukan yaitu dengan cara pemanfaatan beras menir menjadi hasil olahan seperti tepung beras yang juga memiliki nilai ekonomi yang cukup ini. Hal ini sejalan dengan hasil penelitian Rachmat \& Suismono, (2016). Menurut Putri et al. (2013), produk sampingan dari beras seperti menir dapat dijadikan produk 
sampingan yang dapat menyokong usaha penggilingan padi pada umumnya.

\section{KESIMPULAN}

Dari hasil penelitian dapat disimpulkan bahwa gabah varietas IPB $3 \mathrm{~S}$ memiliki kadar air sebesar $14.55 \%$, gabah hampa 1.64\%, butir mengapur (gabah muda) sebesar $3.12 \%$, butir rusak (kuning) sebesar $4.46 \%$ dan butir merah sebesar $0 \%$. Sedangkan komponen mutu fisik beras varietas Ciherang memiliki kadar air sebesar $14.3 \%$, butir kepala sebesar $66.73 \%$, butir patah sebesar $24.18 \%$, butir menir sebesar $7.21 \%$, butir mengapur sebesar $1.51 \%$, butir kuning (rusak) sebesar $0.21 \%$, butir merah sebesar $0.01 \%$, benda asing $0 \%$ serta butir gabah $0 \%$.Pemutuan gabah varietas IPB 3S berada pada kategori gabah Mutu II (sesuai SNI gabah 1987) dengan syarat dilakukan penurunan kadar air sebesar $0.55 \%$, sedangkan beras varietas padi Ciherang tidak sesuai dengan SNI beras dikarenakan tingginya persentase menir.

\section{DAFTAR PUSTAKA}

David H, J., \& Kartinaty, T. (2019). 钢 Karakteristik Mutu Beras Di Berbagai Penggilingan Pada Sentra Padi Di Kalimantan Barat. Journal TABARO, 3(1), 276-286. https://doi.org/10.35914/tabaro.v3i1. 197

Hasbi. (2012). Perbaikan Teknologi 尌 Pascapanen Padi di Lahan Suboptimal. Jurnal Lahan Suboptimal, 1(2), 186-196.

Hasbullah, R., \& Dewi, A. (2009). Kajian 钢 Pengaruh Konfigurasi Mesin Penggilingan terhadap Rendemen dan Susut Giling Beberapa Varietas Padi. Jurnal Keteknikan Pertanian, 23(2), 21579. https://doi.org/10.19028/jtep.023.2. $\% 25 \mathrm{p}$
Indrasari, S. D., Rakhmi, A. T., Subekti, E., \& Kristamtini, K. (2016). Mutu Fisik, Mutu Giling dan Mutu Fungsional Beras Varietas Lokal Kalimantan Barat. Jurnal Penelitian Pertanian Tanaman Pangan, 35(1), 19.

https://doi.org/10.21082/jpptp.v35n1 .2016.p19-28

Kumar, A., Priyadarshinee, R., Roy, A., Dasgupta, D., \& Mandal, T. (2016). Current techniques in rice mill effluent treatment: Emerging opportunities for waste reuse and waste-to-energy conversion. Chemosphere, 164(2016), 404-412. https://doi.org/10.1016/j.chemosphe re.2016.08.118

Mardiah, Z., Rakhmi, A. T., Indrasari, S. ED., \& Kusbiantoro, B. (2016). Evaluasi Mutu Beras dalam Penentuan Pola Preferensi Konsumen terhadap Beras di Pulau Jawa. Jurnal Penelitian Pertanian Tanaman Pangan, 35(3), 163. https://doi.org/10.21082/jpptp.v35n3 .2016.p163-172

Munarso, S. J., Kailaku, S. I., \& Indriyani, ER. (2020). Mutu fisik beberapa segmen beras: subsidi, non subsidi, dan impor. Jurnal Standardisasi, 22(2), 85-94. https://js.bsn.go.id/index.php/standa rdisasi/article/view/790/pdf

Nugraha, S. (2009). Evaluasi Mutu Beras di Propinsi Jawa Barat, Jawa Tengah, dan Jawa Timur Hasil Panen Musim Kemarau 2007. Buletin Teknologi Pasca Panen, 5, 56-60.

Putri, T. A., Kusnadi, N., \& Rachmina, D. 自 (2013). Kinerja Usaha Penggilingan Padi, Studi Kasus Pada Tiga Usaha Penggilingan Padi Di Cianjur, Jawa Barat. Jurnal Agribisnis Indonesia, 
1(2),

143.

https://doi.org/10.29244/jai.2013.1.2 .143-154

Rachmat, R., \& Suismono. (2016). Model 钢 Penggilingan Padi Terpadu Untuk Meningkatkan Nilai Tambah. Buletin Teknologi Pasca Panen, 8(2), 315330 .

Sarastuti, N., Ahmad, U., \& Sutrisno, N. 琶 (2019). Analisis Mutu Beras Dan Penerapan Sistem Jaminan Mutu Dalam Kegiatanpengembangan Usaha Pangan Masyarakat. Jurnal Penelitian Pascapanen Pertanian, 15(2), 63. https://doi.org/10.21082/jpasca.v15n 2.2018.63-72

Sartika, N. D., \& Ramdhani, Z. (2018). 镐 Kajian Penggunaan Mesin Penggiling Mobile Terhadap Mutu Beras Untuk Beberapa Varietas Padi Di Kabupaten Sumbawa Barat (Study on Mobile Milling Machine Utilization in Rice Quality of Several Paddy Variety at Sumbawa Barat Regency). Jurnal Ilmiah Rekayasa Pertanian Dan Biosistem, 6(1), 5359.

https://doi.org/10.29303/jrpb.v6i1.7 2

Setiawati, D. (2020). Faktor-Faktor yang 铇 Mempengaruhi Kualitas Gabah Di Indonesia. Jurnal Ekonomi Pertanian Dan Agribisnis (JEPA), 4(4), 783-793. https://doi.org/10.21776/ub.jepa.202 0.004.04.08

Thahir, R. (2010). Revitalisasi 钢 Penggilingan Padi Melalui Inovasi Penyosohan Mendukung Swasembada Beras Dan Persaingan Global. Pengembangan Inovasi Pertanian, 3(3), 171-183.
Ulfa, R., Hariyadi, P., Tjahja Muhandri, D., 尌 Magister Profesi Teknologi Pangan, P., Pascasarjana, S., Pertanian Bogor, I., Ilmu dan Teknologi Pangan, D., \& Teknologi Pertanian, F. (2014). Rendemen Giling dan Mutu Beras pada Beberapa Unit Penggiling Padi Kecil Keliling di Kabupaten Banyuwangi. 1(1), 26-32.

Umar, S. (2011). Pengaruh Sistim 尌 Penggilingan Padi terhadap Kualitas Giling Di Sentra Produksi Beras Lahan Pasang Surut. Jurnal Teknologi Pertanian, 7(1), 9-17.

Yuriansyah, Y. (2017). Milled Rice 尌 Quality Evaluation of Some Hope Strain Rice Field Rice (Oryza sativa L.). Jurnal Penelitian Pertanian Terapan, 17(1), 66-76. https://doi.org/10.25181/jppt.v17i1. 42 